\title{
Effect of Sm concentration on optical and electrical properties of CdSe nanocrystalline thin film
}

\author{
K.K. PathaK ${ }^{1, *}$, Mimi Akash Pateria ${ }^{2}$, Kusumanjali Deshmukh ${ }^{2}$, Piyush Jha ${ }^{1}$ \\ ${ }^{1}$ Department of Applied Physics, Raipur Institute of Technology, Chhatauna, Mandir Hasuad, \\ Raipur 492101, Chhattisgarh, India \\ ${ }^{2}$ Department of Applied Physics, Shri Shankaracharya Group of Institutions, Junwani, Bhilai, Chhattisgarh, India
}

\begin{abstract}
Present paper reports optical and electrical properties of samarium doped CdSe nanocrystalline thin film which was grown on a glass substrate by chemical bath deposition method (CBD). X-ray diffraction (XRD) analysis revealed that the deposited films were nanocrystalline with sphalerite cubic structure. The average crystallite size calculated from FWHM of XRD peaks was found to be $10.11 \mathrm{~nm}$. The bandgap of the Sm doped CdSe nanocrystalline thin films was calculated to be $1.91 \mathrm{eV}$ to $2.22 \mathrm{eV}$. The optical absorption edge of undoped (pure) and Sm doped CdSe films was obtained between $650 \mathrm{~nm}$ to $640 \mathrm{~nm}$ showing blue shift as compared to bulk CdSe. Sm doping further enhanced the photoconductivity of these films. The I-V characteristic confirmed the suitability of prepared films for photosensor applications.
\end{abstract}

Keywords: CdSe:Sm nanocrystalline thin film; XRD; absorption; photoluminescence

\section{Introduction}

Cadmium selenide (CdSe) is a II-VI group compound semiconductor material. Its excellent performance and suitable properties such as band gap, high absorption coefficient and high photosensitivity make it useful in the applications in electronic and optoelectronic devices, such as laser diodes, high-efficiency solar cells, nanosensors, $\gamma$-ray detectors and biomedical imaging devices [1-4]. CdSe has a direct band gap with high absorption coefficient near the band edge, which allows its use in thin film devices; it is mainly interesting for the applications in solar hybrid systems [5].

CdSe thin films have been prepared by various film deposition techniques, such as sputtering [6], electron beam evaporation [7-9], photoelectrochemical method [10], MOCVD [11], and chemical bath deposition (CBD) [12-14]. For the production, chemical bath deposition (CBD), an inexpensive and relatively simple method of deposition of nanocrystalline thin films, is widely

*E-mail: krishnakumarpathak81@gmail.com used $[14,15]$. Advantages of CBD method is that it uses very simple equipment, does not require high temperature or pressure, ensures high reproducibility and is environment friendly. Film thickness or stoichiometry is controlled by optimization of various deposition conditions, such as temperature, time, concentration of reactants, complexing salt concentration etc. CBD method is useful for preparing smooth and uniform semiconductor layers and has been used mainly for metal selenides. CBD method found its sound application in photovoltaics. To increase the performance of CdSe nanocrystalline thin films, many researcher used the dopant impurities and made thin film of CdSe:Te [16], CdSe:In [17, 18], CdSe:Hg [19], $\mathrm{CdSe}: \mathrm{Cu}$ [20], and CdSe:Mn [21], etc. Present work is intended to increase the performance of nanocrystalline thin films by lanthanides doped in II-VI semiconductor. To increase the efficiency and performance of photovoltaic devices and displays, we have used our new approach to dope samarium $\left(\mathrm{Sm}^{3+}\right)$ in CdSe nanocrystalline thin films. This paper reports the optical and electrical properties of Sm doped CdSe nanocrystalline thin films prepared by chemical bath deposition method. 


\section{Experimental}

The precursor solution for deposition of the films was prepared by mixing cadmium acetate $\left(\mathrm{Cd}\left(\mathrm{CH}_{3} \mathrm{COO}\right)_{2}\right)$, sodium selenosulfate $\left(\mathrm{Na}_{2} \mathrm{SeSO}_{3}\right)$, triethanolamine (TEA), and ammonia in appropriate amounts. The sodium selenosulfate was prepared by refluxing $4 \mathrm{~g}$ of selenium powder with $50 \mathrm{~g}$ of sodium sulfite $\left(\mathrm{Na}_{2} \mathrm{SO}_{3}\right)$ in $250 \mathrm{~mL}$ of doubled distilled water at $80{ }^{\circ} \mathrm{C}$ for $6 \mathrm{~h}$. For deposition of undoped (pure) CdSe films, a bath mixture was prepared in a $100 \mathrm{~mL}$ beaker by addition of aqueous solution of cadmium acetate, $2 \mathrm{~mL}$ TEA (triethenolamene), $10 \mathrm{~mL}$ of $30 \%$ ammonia solution and $7 \mathrm{~mL}$ of sodium selenosulfate. Ultrasonically cleaned glass substrates were then dipped into the bath solution at an angle of $20^{\circ}$ relative to the wall of the beaker. The reaction mixture was maintained at a temperature of $70{ }^{\circ} \mathrm{C}$ for deposition. Ammonia solution was added into the mixture for adjusting the $\mathrm{pH}$ to 11 . Substrates coated with CdSe films were removed from the bath after a deposition time of $6 \mathrm{~h}$. Different volumes of $0.01 \mathrm{M}$ aqueous solution of samarium nitrate $\left(\mathrm{Sm}\left(\mathrm{NO}_{3}\right)_{2}\right)$ were added to the original mixture. Deposited substrates were washed with doubled distilled water and allowed to dry under ambient conditions before film characterization. The deposited thin films were uniform, well adherent and red-orange in color.

The undoped and Sm doped CdSe thin films were characterized using PANalytical $3 \mathrm{~kW}$ X'Pert powder XRD - multifunctional diffractometer with $\mathrm{Cu} \mathrm{K} \alpha$ radiation source $(\lambda=1.5406 \AA$ and $2 \theta$ range $=10^{\circ}$ to $120^{\circ}$ ). The surface morphology of $\mathrm{CdSe}: \mathrm{Sm}$ thin films was investigated a by scanning electron microscope (SEM), model No. Zeiss EVO 18. The UV-Vis absorption spectra were recorded with a Shimadzu UV-Vis spectrophotometer (model: UV-1700). Photoluminescence spectra were measured with Shimadzu RF5301 spectofluorometer. The film thickness was measured by gravimetric method using the equation [22]:

$$
t=\frac{m}{\rho A}
$$

where $\mathrm{t}$ is film thickness, $\mathrm{m}$ is mass of deposited $\mathrm{CdSe}, \rho$ is density of $\mathrm{CdSe}=5.816 \mathrm{~g} / \mathrm{cm}^{3}$ and A is area of the sample. The thickness of the CdSe:Sm nanocrystalline thin film in the present investigation was found to be around $240 \mathrm{~nm}$.

\section{Results and discussion}

X-ray diffraction was used to study the structure of the deposited thin films. Obtained peaks were matched with JCPDS File No. 19-191 and JCPDS File No.65-2891, and were found to match with the planes of cubic structure. The X-ray diffraction (XRD) spectra of undoped and Sm doped CdSe thin films are shown in Fig. 1. As shown in the figure, the diffraction patterns exhibit the highest intensity reflections along the (llll 111$)$ plane and two weak reflections along the (2 20$)$ and (3 111$)$ planes at $25.39^{\circ}, 42.14^{\circ}$ and $49.08^{\circ}$ for undoped $\mathrm{CdSe}$ and $25.31^{\circ}, 41.93^{\circ}$, and $49.61^{\circ}$ for Sm doped CdSe nanocrystalline thin films, respectively. The results indicate that the prepared films are crystalline and composed of $\mathrm{CdSe}$ in cubic phase with preferred orientation along the $\left(\begin{array}{lll}1 & 1 & 1\end{array}\right)$ plane. The XRD data show that there is no shift in the peaks positions, only peak intensity is varied. This indicates an increase in crystallinity of the films with doping of $\mathrm{Sm}\left(\mathrm{NO}_{3}\right)_{2}$. d-spacing and lattice constant were calculated for observed peaks. The lattice parameter a of the CdSe:Sm thin films was calculated for the cubic structure using the relation:

$$
a=d_{h k l}\left(h^{2}+k^{2}+l^{2}\right)^{1 / 2}
$$

The average value of lattice parameter was found to be $6.089 \AA$.

XRD data were used to determine the particle size D. The average particle sizes of the deposited films were calculated from the highest intensity peak using the Debye-Scherrer equation [23-25]:

$$
D=\frac{k \lambda}{\beta \cos \theta}
$$

where $\mathrm{D}$ is the particle size of CdSe nanoparticles, $\lambda$ is the $\mathrm{X}$-ray wavelength $(1.5406 \AA), \theta$ is Bragg diffraction angle, $\beta$ is the full-width at halfmaximum (FWHM) of the peak, and $\mathrm{k}$ is a constant 


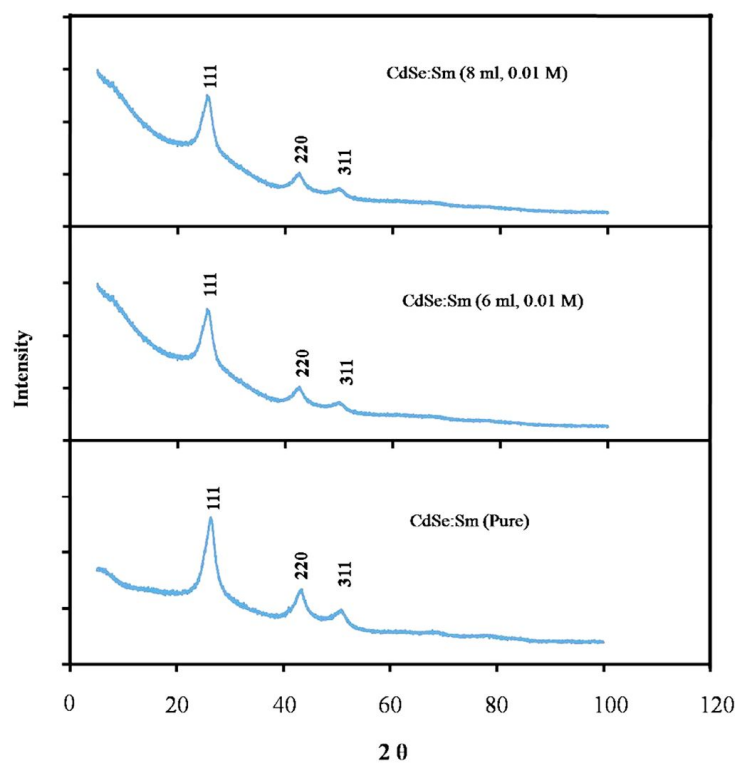

Fig. 1. XRD patterns of CdSe and CdSe:Sm nanocrystalline thin films.

usually taken equal to 0.9 . The average crystallite size in the present investigation was found to be $10.11 \mathrm{~nm}$.

SEM was used to investigate surface morphology of undoped and Sm doped CdSe nanocrystalline thin films deposited at $70{ }^{\circ} \mathrm{C}$ for $6 \mathrm{~h}$. The morphology of the thin films was uniform, dense and the film was well adherent to the substrate surface. Nanosphere-like surface morphology was observed in both the cases [15]. The surface was not completely covered with nanospheres and some gaps were observed between the spheres.

The small spherical grains are interconnected with each other which led to formation of large surface area which may be the reason for the increase of conductivity of the sample. No change in particle size for undoped and $\mathrm{Sm}\left(\mathrm{NO}_{3}\right)_{2}$ doped thin films was noticed, only variation in surface density was observed due to the change in solution composition with the addition of different amounts of impurity. This result was confirmed by the absorption study as there was no change in the position of band edge.

The optical absorption spectra of the films deposited onto glass substrates were studied

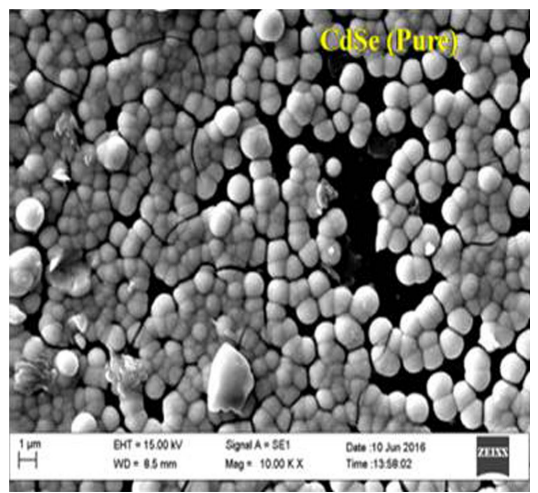

(a)

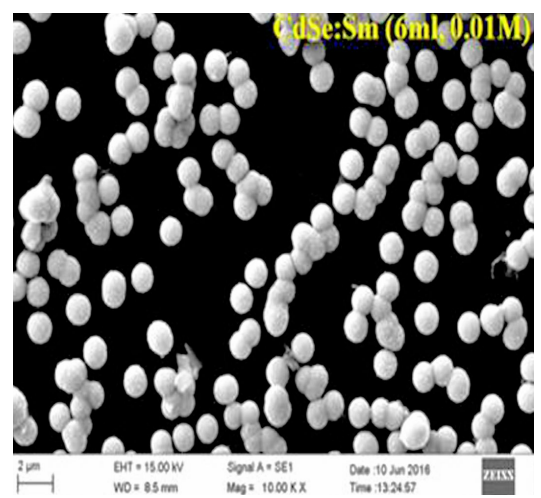

(b)

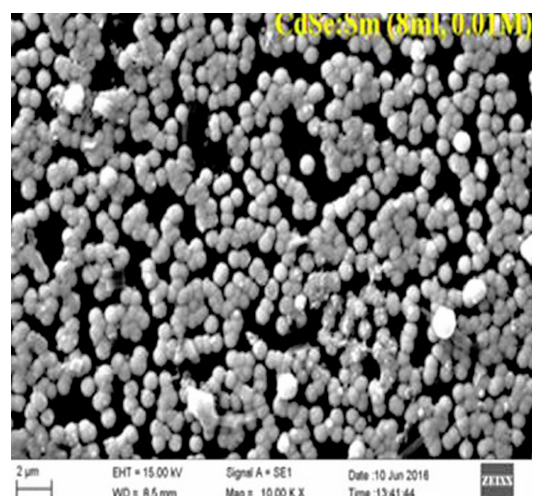

(c)

Fig. 2. SEM images of CdSe and CdSe:Sm nanocrystalline thin films.

in the wavelengths range of $200 \mathrm{~nm}$ to $800 \mathrm{~nm}$. Fig. 3 shows the optical absorbance spectra of undoped and $\mathrm{Sm}$ doped $\mathrm{CdSe}$ nanocrystalline thin films prepared from different volumes of samarium nitrate. The absorption data were analyzed using the relation:

$$
\alpha h v=A\left(h v-E_{g}\right)^{n}
$$


where hu is photon energy, $\mathrm{E}_{\mathrm{g}}$ is band gap and $\mathrm{A}$ is a constant. The values of $n$ in equation 4 are $1 / 2$, $2,3 / 2$ and 3 for allowed direct, allowed indirect, forbidden direct and forbidden indirect transitions, respectively. The linear nature of the plot indicates the existence of the direct transition. The band gap energy was determined from Tauc plot $(\alpha h v)^{2}$ vs. $h v$ for the direct band gap.

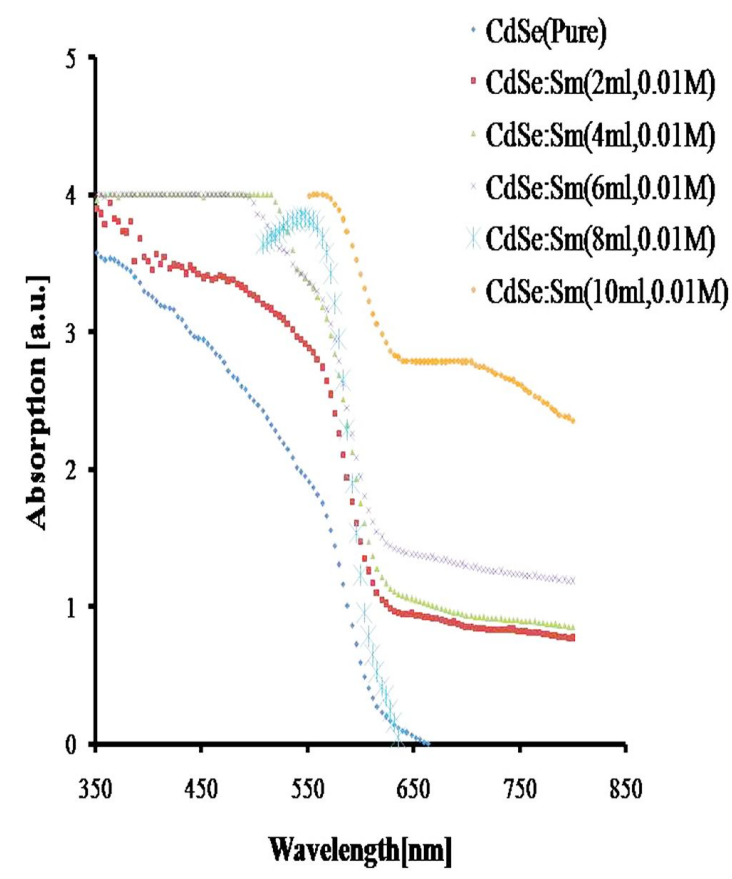

Fig. 3. Absorption spectra of $\mathrm{CdSe}$ and $\mathrm{CdSe}: \mathrm{Sm}$ nanocrystalline thin film.

Fig. 4 shows the Tauc plots for the undoped and $\mathrm{Sm}$ doped $\mathrm{CdSe}$ nanocrystalline thin films. The bandgap was determined by extrapolating the straight line portion to the energy axis. The intercept of this gives the optical band gap. The optical bandgap for pure CdSe and different volumes of $\mathrm{Sm}\left(\mathrm{NO}_{3}\right)_{2}$ doped $\mathrm{CdSe}$ thin film obtained from the Tauc plots were found to range from 1.91 to $2.22 \mathrm{eV}$ which is higher than the bulk CdSe $(1.75 \mathrm{eV}$ to $1.8 \mathrm{eV})$ as expected [13]. This increase in the band gap can be associated with the decrease in particle size, affirming the nanocrystallinity of the prepared sample.
As the doping volume has increased from $2 \mathrm{~mL}$, absorption in the infra and far infrared region has changed. The samples prepared with $8 \mathrm{~mL}$ of $\mathrm{Sm}\left(\mathrm{NO}_{3}\right)_{2}$ shows minimum absorption in IR region with a sudden increase at $645 \mathrm{~nm}$ which is quite near to that of undoped film. The films prepared with $10 \mathrm{~mL}$ volume of $\mathrm{Sm}\left(\mathrm{NO}_{3}\right)_{2}$ shows maximum absorption among all in IR region with an edge at $640 \mathrm{~nm}$. Thus, the CdSe:Sm films prepared with $8 \mathrm{~mL}$ volume of $\mathrm{Sm}\left(\mathrm{NO}_{3}\right)_{2}$ can be considered as more suitable for photovoltaic applications.

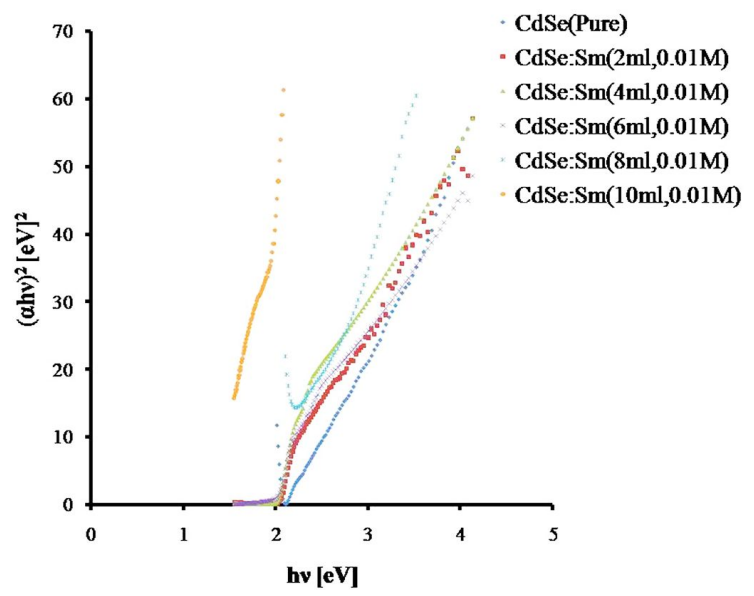

Fig. 4. Plot of $(\alpha h v)^{2}$ vs. hv (derived from Fig. 3).

No appreciable shift in the band edge is noticed in the various Sm doped and undoped CdSe films indicating that doping has not affected the band structure of the deposited crystalline film.

At the same time, it is observed that the band gap values calculated from the Tauc plot are much higher than those reported for the bulk samples. It could be stated that the slow precipitation of $\mathrm{Cd}$ and Se ions in the bath and their condensation on the substrate caused ion by ion growth of CdSe films with particle sizes of the order of nanometers.

As the volume of $\mathrm{Sm}\left(\mathrm{NO}_{3}\right)_{2}$ increased from $6 \mathrm{~mL}$ to $10 \mathrm{~mL}$, the color of deposited films became paler because of the increase of Sm concentration in the CdSe material.

Fig. 5 shows the photoluminescence (PL) spectra of undoped $\mathrm{CdSe}$ and $\mathrm{Sm}$ doped CdSe nanocrystalline thin films obtained 
at an excitation wavelength of $395 \mathrm{~nm}$. It shows the emission at $601 \mathrm{~nm}$ for undoped and $\mathrm{CdSe}$ thin films doped with different volumes of Sm. No shift is observed in the position of the peak in photoluminescence emission spectra for various concentrations of samarium nitrate doped thin films. Only intensity variation is observed due to trapping of electrons in presence of $\mathrm{Sm}\left(\mathrm{NO}_{3}\right)_{2}$ solution in the prepared material. This might have happened because an impurity energy level is formed below the conduction band of undoped CdSe. It was reported that this kind of band-edge luminescence can be caused by the recombination of excitons and/or shallowly trapped electron-hole pairs [26, 27].

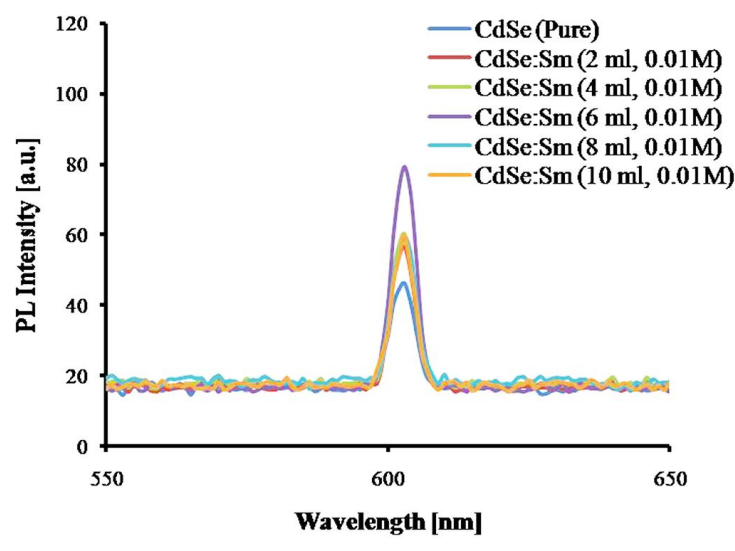

Fig. 5. Photoluminescence spectra of $\mathrm{CdSe}$ and CdSe:Sm nanocrystalline thin films.

Fig. 6 shows I-V characteristics obtained for the pure $\mathrm{CdSe}$ and $\mathrm{Sm}$ doped CdSe thin films for different illumination intensities. An area of $0.5 \mathrm{~cm}^{2}$ of CdSe thin film on the glass substrate was selected for electrical studies and two silver electrode were applied at a distance of $0.2 \mathrm{~cm}$ to ensure good neutral electrical contacts to the films. The linearity of the plots suggests the formation of ohmic contacts at metal-semiconductor $(\mathrm{Ag} / \mathrm{CdSe}$ and $\mathrm{Ag} / \mathrm{CdSe}: \mathrm{Sm})$ junctions, indicating that the work function of metal $\mathrm{Ag}$ is higher than that of semiconductor CdSe. This aligns the Fermi level of $\mathrm{Ag}$ with the upper band edge of valence band. The resistivity decreases with an increase in illumination intensity.

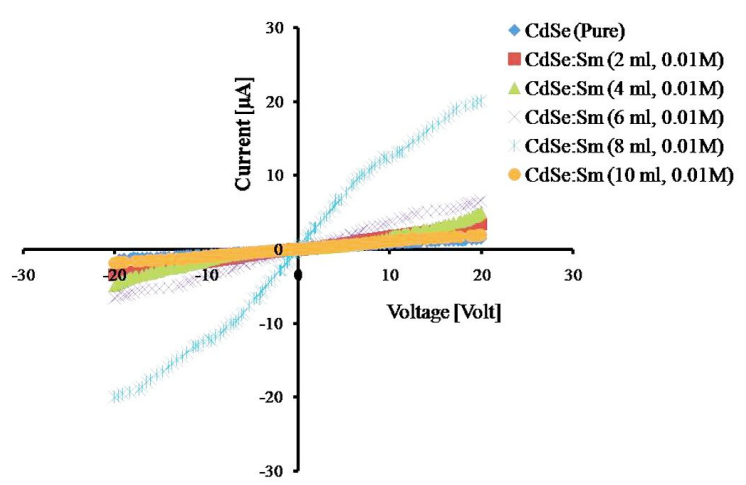

Fig. 6. Current-voltage (I-V) characteristics obtained for $\mathrm{CdSe}$ and $\mathrm{CdSe}: \mathrm{Sm}$ nanocrystalline thin films deposited on glass substrates.

Fig. 6 shows the variation of current with the doping of different volumes of $\mathrm{Sm}\left(\mathrm{NO}_{3}\right)_{2}$. It is observed that the current increases with increasing in the volume of impurity. The electrical resistivity $\rho$ of the deposited thin film was calculated using the relation:

$$
\rho=2 \pi s \frac{V}{I}
$$

where $\mathrm{s}$ is the distance between the inner pair of electrodes which is $2 \mathrm{~mm}$. The electrical resistivity is observed to decrease with doping of Sm ions. The results are in agreement with the literature [28].

\section{Conclusions}

The undoped and Sm doped CdSe nanocrystalline thin films were prepared by chemical bath deposition method. X-ray diffraction patterns of Sm doped CdSe nanocrystalline thin films clearly show that the film has a sphalerite cubic (zinc blende type) structure. The optical absorption edge value of pure and $\mathrm{Sm}$ doped $\mathrm{CdSe}$ films ranged from $650 \mathrm{~nm}$ to $640 \mathrm{~nm}$ showing blue shift as compared to the bulk CdSe. Band gap values were calculated from absorption spectra and were found to be $1.91 \mathrm{eV}$ to $2.22 \mathrm{eV}$ which is higher than the value for bulk CdSe (1.75 eV to $1.8 \mathrm{eV})$. Photoluminescence of Sm doped CdSe nanocrystalline thin films was recorded and the strongest PL intensity 
was found at $601 \mathrm{~nm}$. This might have happened because of another energy level formed below the conduction band of undoped CdSe. The electrical resistivity of the thin films was found to decrease with doping level of Sm ions. The prepared films have a sufficient potential to be used for solar cell applications.

\section{References}

[1] Califano M., Zunger A., Franceschetti A., Appl. Phys. Lett., 84 (2004), 2409.

[2] Schaller R.D., Petruska M.A., Klimov V.I., Appl. Phys. Lett., 87 (2005), 253102-1.

[3] Hendry E., Koeberg M., Wang F., Zhang H., Mello de Donega C., Vanmaekelbergh D., Bonn M., Phys. Rev. Lett., 96 (2006), 057408-1.

[4] Roth M., Nucl. Instrum. Meth. A, 283 (1989), 291.

[5] Vorobiev Yu., González-Hernández J., VoroBiev P., Bulat L., Sol. Energy, 80 (2006), 170.

[6] Moersch G., Rava P., Schwarz F., PaCCagnella A., IEEE T. Electron. Dev., 36 (1989), 449.

[7] Murali K.R., Sivaramamoorthy K., Asath BaHADUR S., KotTAisAmy M., Chalcogenide Lett., 5 (2008), 249.

[8] Mishra S., Kshatri D.S., Khare A., Tiwari S., DWIVEDI P.K., Mat. Lett., 183 (2016), 191.

[9] Mishra S., Kshatri D.S., Khare A., Tiwari S., DWIVEDI P.K., Mat. Lett., 198 (2017), 101.

[10] Pawar S.M., Moholkar A.V., Rajpure K.Y., Bhosale C.H., J. Phys. Chem. Solids, 67 (2006), 2386.

[11] Chae D.Y., Seo K.W., LeE S.S., Yoon S.H., Shim I.W., Bull. Korean Chem. Soc., 27 (2006), 762.

[12] Deshrande M.P., GARG N., BhatT S.V., SAKARIYA P., CHAKI S.H., Mat. Sci. Semicon. Proc., 16 (2013), 915.
[13] Lokhande C.D., LeE E.H., Jung K.D., Joo Q.S., Mater. Chem. Phys., 91 (2005), 200.

[14] Kale R.B., LoKhande C.D., Semicond. Sci. Techol., 20 (2005), 1.

[15] Metin H., Erat S., Ari M., Bozoklu M., Optoelectron. Adv.Mat., 2 (2008), 92.

[16] Islam R., BanerJee H.D., RaO D.R., Thin Solid Films, 266 (1995), 215.

[17] Perna G., Capozzi V., Minafra A., Pallara M., Ambrico M., Eur. Phys. J.B, 32 (2003), 339.

[18] Sharma K., Al-Kabbi A.S., Saini G.S.S., TriPATHI S.K., J. Alloy. Compd., 564 (2013), 42.

[19] Bhuse V.M., Mat. Chem. Phys. B, 91 (2005), 60.

[20] Sharma K., Alkabbi A.S., Saini G.S.S., Tripathi S.K., J. Alloy. Compd., 540 (2012), 198.

[21] Shinde S.K., Dubal D.P., Ghodake G.S., Fulari V.J., J. Electroanal. Chem., 727 (2014), 179.

[22] Ubale A.U., Ibrahim S.G., Arch. Phys. Res., 4 (2013), 37.

[23] Cullity B.D., Stock S.R., Elements of X-Ray Diffraction, Prentice Hall, New Jersey, 2001.

[24] Cullity B.D., Elements of X-ray Diffraction, Addition-Weasley, London, 1978.

[25] Williamson G.B., Smallman R.C., Philos. Mag., 1 (1956), 34.

[26] Wang G.Z., Chen W., Liang C.H., Wang Y.W., Meng G.W., Zhang L.D., Inorg. Chem. Commun., 4 (2001), 208.

[27] Wang W.Z., Geng Y., Yan P., LiU F.Y., Xie Y., QIAN Y.T., Inorg. Chem. Commun., 2 (1999), 83.

[28] Erat S., Metin H., Ari M., Mat. Chem. Phys., 111 (2008), 114.
Received 2017-05-17 Accepted 2019-01-11 